\title{
O coordenador pedagógico frente aos desafios da constituição de sua profissionalidade
}

The pedagogical coordinator facing the challenges of the constitution of his professionality

\begin{abstract}
Camila Manarin Discente do curso de Mestrado em Educação, na linha de pesquisa Cultura, Processos Educativos e Formação de Professores, pela Universidade Estadual do Oeste do Paraná- UNIOESTE. camilla_lazzarotto@hotmail.com
\end{abstract}

Angela Maria Silveira Portelinha Doutorado em Educação pela Universidade Federal do Rio Grande do Sul (UFRGS) e professor adjunto da Universidade Estadual do Oeste do Paraná. (UNIOESTE), curso de Pedagogia e no Programa de Pós-graduação em Educação - Mestrado. amportelinha@yahoo.com.br

Resumo: Num cenário educativo que vem sofrendo mudanças de acordo com os interesses hegemônicos de uma sociedade neoliberal, a formação do pedagogo escolar, entendido aqui como Coordenador Pedagógico, também se modifica. O presente artigo propõe uma reflexão sobre a formação deste profissional a partir da constituição histórica da profissão, estabelecendo relações com os conceitos de profissionalidade e profissionalismo. A opção metodológica baseia-se na pesquisa bibliográfica e na análise documental respaldada na produção teórica sobre a identidade do Coordenador Pedagógico, como também a profissão do Coordenador Pedagógico num contexto histórico e social com base nas categorias emergente, dominante e residual. $\mathrm{O}$ texto destaca a necessidade de repensar as políticas de formação docente juntamente com questões relativas às particularidades da atuação dos coordenadores pedagógicos.

Palavras-chave: Coordenador Pedagógico. Formação de Professores. Pedagogo. Profissionalidade.

Abstract: In an educational stage that has been affected by changes due to neo-liberal society hegemonic interests, the school pedagogue's training, taken in this paper as the pedagogical coordinator, also changes. In this paper we aim to reflect on this professional training based on the historical constitution of the profession, setting up relations with the concepts of professionality and professionalism. Our methodological approach is based on a bibliographical research and on a documental analysis grounded on a theoretical production over the pedagogical coordinator's identity, but also his profession in a historical and social context based in the emerging, dominant, and residual categories. We highlight the need of rethinking teaching training policies with questions related to some particularities regarding pedagogical coordinators' work.

Keywords: Pedagogical Coordinator. Teacher Training. Pedagogue. Professionality. 


\section{Introdução}

As escolas de educação básica estão repletas de profissionais da educação com formações que contemplam as diversas áreas do conhecimento. Dentre os profissionais responsáveis pelo processo educativo-formativo escolar destacamos o Coordenador Pedagógico. Entendermos que este profissional exerce um papel fundamental na organização e articulação do trabalho pedagógico nas instituições escolares.

É fundamental reconhecer que o Coordenador Pedagógico assume diferentes funções dependendo do sistema de ensino a que está vinculado. Por essa razão, muitas vezes associa-se a identidade do Coordenador Pedagógico à identidade do pedagogo ou a um professor que integra a gestão escolar.

De acordo com Libâneo (2010), pedagogo é o profissional formado nos cursos de pedagogia para atuar em diversas áreas educativas formais, não formais e informais, sendo umas delas a coordenação pedagógica, O curso de pedagogia, porém, deve ter o caráter de formar um profissional qualificado que esteja preparado para atuar em várias instâncias educativas, não se reduzindo apenas à gestão, supervisão e coordenação pedagógica da escola, ampliando para um caráter de demanda educativa social.

Essa ideia nos permite reforçar que o trabalho do Coordenador Pedagógico na gestão também pode ser diverso por se tratar de um campo mais administrativo e pedagógico, não se restringindo ao espaço escolar. Sendo assim, o Coordenador Pedagógico pode atuar na direção, na coordenação, na orientação escolar, dentre outras áreas que contemplem a gestão em outros espaços educativos.

No entanto, vale observar que a formação inicial do Coordenador Pedagógico se associa à identidade do Curso de Pedagogia que, historicamente, sofreu diversas alterações relativas ao perfil profissional. De certo modo isto influenciou a profissionalidade e a categorização da profissão e os espaços de atuação.

Para isso, tornou-se necessário problematizarmos a questão nos seguintes termos: Como este profissional se constituiu ao longo da história? O que foi renovado nas políticas públicas a partir das mudanças sociais e políticas? O que permanece e o que predomina neste campo? Nesse sentido, este artigo busca discutir a configuração da formação e do trabalho do Coordenador Pedagógico. Para tanto, optamos pela metodologia de pesquisa bibliográfica e documental para explicar e entender as questões elucidadas, dialogando com autores que pesquisam o trabalho do Coordenador Pedagógico. Entre estes autores, citamos Libâneo (2010) e Franco (2008), quando também estabelecemos uma relação com os conceitos de profissionalidade e profissionalismo de 
Contreras (2012). No presente texto, lidamos também com a profissão do Coordenador Pedagógico em um contexto histórico e social com base nas categorias emergentes, dominantes e residuais, explicitadas por Williams (1979). Para isso, expomos a nossa reflexão de forma a contemplar o percurso histórico do perfil profissional do Coordenador Pedagógico além da especificidade da profissão diante das amarras do profissionalismo e da profissionalidade docente.

\section{Breve percurso histórico do perfil profissional do Coordenador Pedagógico}

A educação é um fenômeno de abrangência pluridimensional, no sentido de que ocorre em diversos campos nas mais variadas instâncias da sociedade, que foi se transformando ao longo dos anos conforme as demandas sociais existentes. Com a divisão do trabalho e a sociedade industrializada começaram a surgir novas exigências educativas para atender o mercado de trabalho. Da mesma forma, a educação também precisou ser modificada. Portanto, os cursos de pedagogia surgem para atender as demandas sociais em uma luta em defesa da educação pública e de qualidade.

Nesse sentido, para atender uma demanda social, com a promulgação do Decreto $\mathrm{n}$. 1.190/1939, regulamenta-se a criação de uma faculdade de educação, denominada, no documento, de Faculdade de Filosofia, que previa a organização de sessões estruturadas em quatro unidades: ciências, pedagogia e letras organizando uma estrutura formativa no chamado sistema $3+1$, que formava o bacharel em três anos e o licenciado necessitava de mais um ano para cursar a sessão especial de didática geral e, então, obter o grau de licenciado. (Saviani, 2008). Essa organização possibilitava ao egresso do Curso de Pedagogia atuar como técnico em educação e como docente nas escolas normais voltadas à formação dos professores primários.

De acordo com Saviani (2008), posteriormente, em 1962, institui-se o Parecer n. 251, de Valnir Chagas, visando formar os professores primários no ensino superior e os técnicos e especialistas em educação, mantendo a formação nos moldes do sistema 3+1, além de estabelecer a carga horária e as disciplinas que deveriam ser ofertadas. Este parecer foi promulgado logo após a aprovação da lei n. 4024/1961, que apresentava a primeira definição da Lei de Diretrizes e Bases da Educação Nacional (LDBEN), que perdurou até a reforma universitária em 1968, quando se apontaram novas reformulações para o curso.

A lei da reforma universitária - lei n. 5.540/1968 - desencadeia uma nova regulamentação para o curso de pedagogia, estabelecendo, via Parecer n. 252/1969, a estrutura que vigorou até a promulgação da LDBEN n. 9.394/1996. (Saviani, 2008). Com este parecer, é abolida a distinção 
entre bacharelado e licenciatura e são estabelecidas as habilitações. Desse modo, a Resolução n. 02/1969, que acompanha o parecer, estabelece a função do curso de pedagogia: formar professores para o ensino normal e especialistas para as atividades de orientação, administração, supervisão e inspeção no âmbito das escolas e dos sistemas escolares.

Assim, a formação nos cursos de pedagogia se torna estritamente especializada. Ela passa a definir uma formação por habilitações. Ao orientador educacional são oferecidas disciplinas que contemplam aspectos de orientação educacional voltadas ao trabalho com o aluno, à inspeção escolar, disciplinas que contemplam os aspectos direcionados à fiscalização das atividades desenvolvidas na escola, à supervisão escolar. A sua formação passa a envolver disciplinas que correspondam ao trabalho da supervisão direta com os professores e a administração escolar, disciplinas relativas aos aspectos burocrático-administrativo escolares. Este modelo de formação profissional foi alvo de críticas por acentuar a fragmentação do processo pedagógico, a dicotomia entre teoria e prática e a dualidade entre planejar e executar.

Kuenzer (2006) pondera que, mesmo havendo críticas a respeito da fragmentação da formação dos profissionais para atuar na organização do trabalho pedagógico, no caso o pedagogo especialista, existe uma carência ao não se ter esta fragmentação, ao ponto de a junção das especificidades das habilitações em uma única formação, em um único profissional, acarretar a existência de um profissional polivalente, formado para atuar em vários campos da gestão escolar, com uma formação multilateral, abrangendo diferentes aspectos e resultando na falta de identidade profissional.

Esse processo resultou em novos indicativos para o perfil profissional nos cursos de pedagogia, que posteriormente foram propostos pelas Diretrizes Curriculares Nacionais (DCNs). Conforme a Resolução n. 01/2006, do CNE/CP, que institui as Diretrizes Curriculares Nacionais para o Curso de Graduação em Pedagogia (DCNCP), licenciatura, em seu Art. 2.ํㅡ, lemos:

As Diretrizes Curriculares para o curso de Pedagogia aplicam-se à formação inicial para o exercício da docência na Educação Infantil e nos anos iniciais do Ensino Fundamental, nos cursos de Ensino Médio, na modalidade Normal, e em cursos de Educação Profissional na área de serviços e apoio escolar, bem como em outras áreas nas quais sejam previstos conhecimentos pedagógicos. (BRASIL, 2006, p.01?)

Diante dessa nova organização, entendemos que o profissional que o mercado de trabalho exige é um profissional capaz de realizar diversas atividades e de se adequar ao trabalho com flexibilidade e destreza. Logo, o curso de pedagogia, no formato estruturado conforme as DCNs para o Curso de Pedagogia de 2006, contempla a unificação de todas as habilitações num só curso, tendo como base a formação para a docência, em que abrange a educação infantil até os anos finais do ensino fundamental. 
Este modelo de formação do profissional, cujas bases são a docência, a gestão e a pesquisa, é ratificado pela Resolução n. 02/2015, que define as DCNs para a formação inicial em nível superior (cursos de licenciatura, cursos de formação pedagógica para graduados e cursos de segunda licenciatura) e para a formação continuada, acrescentando, em seu texto, o campo específico e/ou interdisciplinar. Logo, a concepção de docência que está sustentada nas DCNs de 2015 é apresentada no Art. 2.. inciso primeiro:

$\int 1^{\circ}$ Compreende-se a docência como ação educativa e como processo pedagógico intencional e metódico, envolvendo conhecimentos específicos, interdisciplinares e pedagógicos, conceitos, princípios e objetivos da formação que se desenvolvem na construção e apropriação dos valores éticos, linguísticos, estéticos e políticos do conhecimento inerentes à sólida formação científica e cultural do ensinar/aprender, à socialização e construção de conhecimentos e sua inovação, em diálogo constante entre diferentes visões de mundo. (BRASIL, 2015, p. 03).

Essa concepção é entendida como a base e a identidade de todos os professores, independentemente de área, etapa, modalidade e espaço de atuação. Isso inclui o Coordenador Pedagógico, uma vez que seu trabalho se volta a articular, juntamente com os professores, diferentes maneiras de encaminhar o processo educativo-formativo no contexto escolar. Consideramos que as reformulações nas leis que regulamentam a educação passam por renovações e aprovações. Entretanto, o que determina as mudanças estruturais ainda são políticas neoliberais tratadas intensamente no cenário educacional, atendendo as demandas do mercado.

Franco (2008) afirma que é preciso que o Coordenador Pedagógico escolar realize seu trabalho a fim de coordenar o pedagógico na escola, e coordenar o pedagógico trata-se especialmente de atuar em função do ensino e aprendizagem na instituição para buscar uma qualidade sempre maior na efetivação deste propósito comum seguindo os compromissos com a comunidade.

Por outro lado, entendemos também que o Coordenador Pedagógico é rodeado de dinamicidade em sua rotina profissional. Ele necessita executar várias tarefas que não cabem a ele, mas por motivos diversos suscita intervenção na efetivação delas.

Nesse sentido, é preciso considerar que a formação inicial que obtiveram os coordenadores das instituições educacionais é parte fundante do processo educativo, para que atuem nesta função expressiva e significativamente. Vale ressaltar a forma como a legislação atual contempla a formação inicial necessária para atuar na docência como Coordenador Pedagógico, ou qualquer outro cargo na área da administração e gestão da instituição de ensino. Assim, o texto redigido na Lei de Diretrizes e Bases da Educação Nacional, de 1996, define, no Art. 64: 
A formação de profissionais de educação para a administração, planejamento, inspeção, supervisão e orientação educacional para a educação básica será feita em cursos de graduação em pedagogia, ou em nível de pós-graduação, a critério da instituição de ensino, garantida, nesta formação, a base comum nacional (BRASIL, 1996, p. 43).

Ainda que a legislação garanta a necessidade de existir uma formação inicial que contemple os aspectos para atuar na gestão, ela não abrange a necessidade de haver uma formação já em nível de graduação, mas podendo haver formação em demais áreas do conhecimento seguido de um curso de pós-graduação na área da gestão escolar.

Outrossim, quando falamos do Coordenador Pedagógico conforme os termos da lei n. 9394/1996, voltamos a visão de fiscalização correspondente ao período da ditadura militar, em que foram criados os cargos de inspeção, supervisão e orientação educacional, para garantir que todos agentes de ensino atuantes na docência ensinassem apenas aquilo que estava de acordo com a racionalidade técnica. Todavia, os cursos de formação para a docência, como os cursos de pedagogia, também precisaram se adequar ao novo formato de gestão, modificando seus componentes curriculares para contemplar as respectivas mudanças.

Por esse motivo é que vale lembrar a importância de identificar os campos de atuação deste profissional, assim como a formação inicial obtida para o exercício da função a fim de que a realização do trabalho ocorra com todas as suas especificidades. Para poder consolidar, de fato, a melhoria na aprendizagem escolar, é preciso que o Coordenador Pedagógico tenha identidade própria, que tenha valorização profissional, condições adequadas de trabalho para, então, conseguir realizar sua função na escola. (Libâneo, 2008).

\section{Do profissionalismo pedagógico à profissionalidade docente}

Para que possamos entender como a função do Coordenador Pedagógico tem se estruturado no contexto histórico brasileiro, precisamos refletir sobre a sua profissionalidade. Para isso, lembramos que o profissionalismo pedagógico está abarcado por contradições que o próprio termo de profissional acarreta. (CONTRERAS, 2012). Por exemplo, na rede municipal de educação do município de Francisco Beltrão, no Paraná, o profissional pedagogo, denominado Coordenador Pedagógico, conforme a lei municipal n. 4.240, é comparado aos profissionais liberais quando tentam enquadrá-lo em alguma categoria profissional. Essa comparação pode se explicar pela descrição das atividades que necessitam desempenhar no exercício da função. Assim, Contreras (2012, p. 61) aponta que "selecionam-se aquelas 
características ou traços, supostamente reunidos por esse tipo de profissional, e a partir deles, se compõe o retrato do profissionalismo".

Quando analisamos os traços ${ }^{1}$ das profissões elencadas por Contreras (2012), percebemos que ao Coordenador Pedagógico é comum concluir que se trata de um semiprofissional. Justificase esse termo por conta da sua falta de autonomia pedagógica, uma vez que o coordenador está cada vez mais condicionado a exercer sua função de acordo com a determinação do estado e/ou município, executando planos de ação estabelecidos pela secretaria de educação e exercendo funções burocráticas no ambiente escolar. Este trabalho simplista é o enfraquecimento do ponto de partida para aquele que se identifica com a profissão:

\begin{abstract}
O resultado é que os professores ocupam uma posição subordinada na comunidade discursiva da educação. Seu papel em relação ao conhecimento profissional representado pelas disciplinas acadêmicas é o de consumidores, não de criadores. Quem detém o status de profissional no ensino é fundamentalmente o grupo de acadêmicos e pesquisadores universitários, bem como o de especialistas com funções administrativas, de planejamento e de controle no sistema educacional. (CONTRERAS, 2012, p. 70).
\end{abstract}

Do mesmo modo, podemos concluir que a função técnica do Coordenador Pedagógico não lhe proporciona o status de profissional; é preciso que este seja também um pesquisador, produtor e articulador do conhecimento sistematizado cientificamente e historicamente, de forma que sua atuação técnica não sobreponha sua formação científica nem a atuação no coletivo escolar. Isto é, numa visão social, de perspectiva do trabalho, só se considera um profissional aquele que produz pesquisas e, portanto, o Coordenador Pedagógico é visto como um mero executor de funções escolares, tanto pelos profissionais da educação quanto pela comunidade local como um todo. E essa desvalorização faz com que esses profissionais tentem se enquadrar nas categorias de traços apontadas por Contreras (2012). Neste sentido, o citado autor escreve:

\footnotetext{
Normalmente, quando se pensa na ideia de "profissão", parece ter-se em mente uma série de características segundo as quais configuramos esse conceito e, por conseguinte, quem são os merecedores de tal denominação. Uma das referências que mais usualmente se manipulam é a imagem daquelas ocupações sobre as quais parece haver um acordo de que nos encontramos diante de "profissionais". Os casos mais típicos são os do médico e do advogado. Precisamente, os estudos mais tradicionais sobre o que caracteriza os profissionais ou o que entender por profissionalismo parecem basear-se nesses mesmos referenciais. Dessa maneira, selecionam-se aquelas características ou traços, supostamente reunidos por esse tipo de profissional, e, a partir deles, se compõe o retrato do profissionalismo. (CONTRERAS, 2012, p. 61).
}

Nessa busca de um perfil profissional a partir de traços, os coordenadores pedagógicos são entendidos como profissionais singulares e, ao mesmo tempo, em uma categoria mais ampla. Singulares porque têm suas particularidades e não podem ser considerados como uma profissão 
qualquer, a partir de traços pré-determinados, especialmente por terem um compromisso com a comunidade escolar, e respectivamente considerada ampla, no sentido de abarcar, em sua formação, a necessidade de um vasto campo de conhecimento, que também é parte fundante da provocação existente na formação do profissional para atuar na área da gestão escolar com a função de Coordenador Pedagógico por considerar que, no trabalho docente, e aqui suscitamos o trabalho pedagógico, implica não apenas em tratar de questões técnicas do trabalho, mas substancialmente por estabelecer um compromisso social.

Para isso, Contreras (2012, p. 84) aponta três dimensões da profissionalidade que tratam desse compromisso com a sociedade, sendo elas a "obrigação moral, o compromisso com a comunidade e a competência profissional". O Coordenador Pedagógico tem a obrigação moral de exercer sua função de forma a atingir o objetivo de articulador do processo de ensino e aprendizagem, comprometido com todo o coletivo escolar. Assim, para que o processo de ensino e aprendizagem se efetive, torna-se necessário o envolvimento com a sociedade e a comunidade na qual a instituição de ensino está inserida, para que seja possível elaborar um plano de ação a partir da realidade dos sujeitos. Por fim, a competência profissional, segundo Contreras (2010, p. 93)

[...] se refere não apenas ao capital de conhecimento disponível, mas também aos recursos intelectuais de que se dispõe com objetivo de tornar possível a ampliação e desenvolvimento desse conhecimento profissional, sua flexibilidade e profundidade. [...] Da mesma forma, ao ser o ensino uma prática social cuja realização não depende só das decisões tomadas pelos docentes em suas salas de aula, mas de contextos mais amplos de influência e determinação, a competência profissional deve ser colocada em relação com a capacidade de compreensão da forma em que estes contextos condicionam e mediam seu exercício profissional, bem como com a capacidade de intervenção nesses âmbitos.

Portanto, a obrigação moral e o compromisso com a comunidade articulados com essa competência profissional expressam um elemento básico para a profissionalidade dos coordenadores pedagógicos.

Quando entendemos as especificidades da profissão, abrimos um leque para que outros olhares sejam estabelecidos e pensados sobre a formação necessária e os conhecimentos fundantes aos profissionais da educação que atuam na gestão das escolas com a função de Coordenador Pedagógico. Possibilitamos também novas categorias de profissionais caracterizados por sua autonomia pedagógica docente, bem como com as relações necessárias que estabelecem na sociedade, intensificando o compromisso moral e, consequentemente, a competência profissional. Desse modo, reconhecemos aquilo que Contreras (2012) expôs ao falar da necessidade de uma profissionalidade docente - e não apenas um profissionalismo pedagógico 
- como requisito para atuar nas diversas dimensões constitutivas do trabalho do Coordenador Pedagógico.

\title{
4 Uma análise das categorias dominante, residual e emergente frente ao trabalho na coordenação pedagógica
}

Partindo do pressuposto de que precisamos entender o todo para compreender as suas particularidades, e vice-versa, consideramos alguns aspectos de nível macrossocial que condicionam a profissionalidade do Coordenador Pedagógico, tais como as políticas educacionais para a gestão e as bases legais e históricas, bem como a exigência de mercado que, consequentemente, molda o profissional da educação. Vemos a necessidade de destacar três categorias de análises, classificadas como fundamentais num processo contra-hegemônico. São elas: a categoria dominante, a categoria residual e a categoria emergente. (Williams, 1979).

Ponderando os destaques históricos realizados na atuação do Coordenador Pedagógico, entendemos que existem características sociais e culturais que, dentro de um processo da totalidade materialista e histórico, são consideradas dominantes em sentido hegemônico, ao que pertencemos enquanto classe. É nesse sentido que escreve Williams (1979, p. 124):

\begin{abstract}
A complexidade de uma cultura se encontra não apenas em seus processos variáveis e suas definições sociais - tradições, instituições e formações - mas também nas interrelações dinâmicas, em todos os pontos do processo, de elementos historicamente variados e variáveis. Naquilo que chamei de análise "de época", um processo cultural é tomado como sistema cultural, com determinadas características dominantes; a cultura feudal ou a cultura burguesa ou uma transição de uma para outra. Essa ênfase nos traços e características dominantes e definidas é importante e com frequência, na prática, efetiva.
\end{abstract}

Já no tocante à categoria de análise chamada residual, pondera-se aquilo que é de relevância e permanência histórica, não considerada como forma arcaica, mas como categoria de elementos que persistem independentemente das transformações políticas, econômicas e culturais que vão ocorrendo na sociedade:

[...] O residual, por definição, foi efetivamente formado no passado, mas ainda está ativo no processo cultural, não só como um elemento do passado, mas como um elemento efetivo do presente. Assim, certas experiências, significados e valores que não se podem expressar, ou verificar substancialmente, em termos da cultura dominante, ainda são vividos e praticados a base do resíduo -cultural bem como social - de uma instituição ou formação social e cultural anterior. (WILLIAMS, 1979, p. 125). 
Por fim, o autor considera como categoria emergente tudo aquilo que surge como novo, com propósito de inovações que antes não haviam sido pensadas, dentro de uma perspectiva de emancipação cultural dos processos sociais. Williams (1979, p 126) escreve:

Por "emergente" entendo, primeiro, que novos significados e valores, novas práticas, novas relações e tipos de relação estão sendo continuamente criados. Mas é excepcionalmente difícil distinguir entre os que são realmente elementos de alguma fase nova da cultura dominante (e nesse sentido "específico da espécie”) e os que lhe são substancialmente alternativos ou opostos: emergente no sentido rigoroso, e não simplesmente novo.

Essas categorias apresentadas ajudam no sentido de pensarmos a totalidade como uma forma de materializar os processos culturais e sociais para entender a hegemonia e fortalecer a luta contra-hegemônica sob uma perspectiva de formação de sujeitos onilaterais. É o que, tendo presente a obra de Marx e Engels, aponta Manacorda (2007, p. 87):

Frente à realidade da alienação humana, na qual todo homem, alienado por outro, está alienado da própria natureza, e o desenvolvimento positivo está alienado a uma esfera restrita, está a exigência da onilateralidade, de um desenvolvimento total, completo, multilateral, em todos os sentidos, das faculdades e das forças produtivas, das necessidades e da capacidade da sua satisfação.

Esta reflexão nos permite formular o seguinte questionamento: Como entender essas categorias remetendo-nos ao trabalho do Coordenador Pedagógico, sempre reafirmado diante de um processo político hegemônico e social?

Conforme as mudanças realizadas ao longo da construção do perfil histórico deste profissional, em uma perspectiva que responde às efetivas mudanças na demanda de profissionais para o mercado de trabalho, configura-se a exigência de funcionários mais aptos para trabalhar com maior agilidade e competência, necessitando menos saberes sobre as linhas de produção, ou saberes mais específicos de seu campo de trabalho na fábrica. Isso gera a necessidade de um profissional especialista para atuar na gestão escolar. Ou seja, conforme as demandas sociais se modificam e o mercado de trabalho vai alterando o perfil profissional, assim também acontece com os profissionais da educação e com as demandas da escola.

Com o Coordenador Pedagógico não é diferente. Considerando todas as reformas educacionais realizadas e traçando um percurso histórico ao trabalho do Coordenador Pedagógico, percebemos que as reformas são concomitantes às mudanças econômicas e ao cenário político. Portanto, fica claro entendermos como categoria dominante no trabalho do Coordenador Pedagógico os processos hegemônicos que ocorrem neste cenário político através das estratégias políticas que modificam, cada vez mais, o campo educacional e que dominam, de certa forma, toda a estrutura educacional do país. 
Em um segundo ponto de análise, podemos considerar residual e, neste caso específico, as características deste profissional, como um trabalhador da categoria semiprofissional (Contreras, 2012), tendo em vista que várias mudanças foram ocorrendo na base legal do trabalho do pedagogo, como também na história e no reconhecimento profissional da função, dentro dos sistemas de ensino. Desse modo, para Contreras (2012, p. 63-64), a definição de uma categoria semiprofissional apresenta-se da seguinte forma:

De acordo com essa definição do que possa ser um profissional, o procedimento é aplicar os traços as diferentes ocupações e, em função disso, determinar de lhes corresponde ou não tal denominação. Assim, quando se compara os professores com essas características, a conclusão mais habitual a que se chega é que a única denominação possível a ser atribuída é a de semiprofissionais, já que se considera que lhes falta autonomia com relação ao Estado que fixa sua prática, carentes de um conhecimento próprio especializado e sem uma organização exclusiva que regule o acesso e o código profissional. Por conseguinte, os traços ideais de serviço (ou vocação), e de autonomia em relação ao cliente (se entendermos aqui como tal os alunos) ou trabalho não rotineiro, não são elementos suficientes para que a docência seja considerada uma profissão.

A falta de uma profissionalidade docente do Coordenador Pedagógico, portanto, como forma de categoria analisada a partir dos traços torna-se residual porque permanece, mesmo sendo implementadas reformas políticas no país.

Finalmente, essa nova face de analisar e configurar o trabalho do pedagogo, sob a perspectiva neoliberal do profissional polivalente, pode ser também compreendida com base nas categorias analíticas de Williams (1979), como emergente, que emerge dessa luta de classes, e diante do cenário político atual, que fragiliza os ideais de emancipação da classe trabalhadora. É nesse sentido que emergente é rigoroso neste caso, e não simplesmente novo como afirma Willians (1979). O que temos de rigoroso no trabalho do Coordenador Pedagógico? E o que se constitui como apenas uma inovação? Essa nova forma de configurar o trabalho do Coordenador Pedagógico de acordo com as políticas a serviço do capitalismo que emergem da hegemonia podem ser um fator ponderante no que se considera rigoroso do trabalho do Coordenador Pedagógico?

Logo, avaliamos que as mudanças nos cenários políticos, econômicos e educativos foram consideráveis e fundantes no processo da constituição do pedagogo com profissional, considerando o contexto histórico; quando analisamos numa totalidade, entendemos que a sociedade é fruto das lutas e tentativas de fugir da opressão da classe dominante que emerge ainda nos polos dos nossos países. Eis a nossa principal função como educadores. 


\section{Considerações finais}

Perceber a necessidade de uma reflexão sob o foco de análise da realidade escolar que vem sendo debatida por pesquisadores da área e entender a relação que se faz com aspectos trazidos por autores que sustentam o debate fortalece a defesa de uma educação pública de qualidade, além de enriquecer o cenário educacional buscando sempre uma formação docente que dê conta das - ou que melhor trabalhe com as - necessidades da formação profissional do Coordenador Pedagógico.

Avaliamos que a formação deste profissional seja cada vez mais discutida e pesquisada nos campos universitários e entre os próprios pedagogos, para que o seu trabalho seja reconhecido e valorizado socialmente, tendo em vista a importância que deve ser dada ao profissional da área, uma vez que desempenha funções representativas e importantes na escola.

Portanto, pensar a formação inicial nos cursos de pedagogia para a gestão escolar é pensar uma sociedade que reconheça este profissional não apenas como um mero executor de tarefas técnicas, mas como um trabalhador que exerce um compromisso com a sociedade a partir da sua competência profissional.

1 Nota explicativa: Os resultados parciais deste estudos foram apresentados e publicados em anais do evento "X simpósio nacional de educação; IV colóquio internacional de políticas educacionais e formação de professores; II encontro de redes de pesquisa em educação", pela Universidade Regional Integrada do Alto Uruguai e das Missões (URI) em Frederico Westphalen- RS, no dia 28 de setembro 2018.

\section{Referências}

BRASIL. Lei de Diretrizes e Bases da Educação Nacional. Lei n. 9.394/1996. Estabelece as diretrizes e bases da educação nacional. Diário Oficial da União, Brasília, 23 dez., 1996.

BRASIL. Diretrizes Curriculares Nacionais para a formação inicial em nivel superior [...]. CNP/CP, Resolução n. ${ }^{\circ}$ 2, julho de 2015.

BRASIL. Diretrizes Curriculares Nacionais para o Curso de Graduação em Pedagogia, licenciatura. CP/CNE, Resolução 01/2006, publicada no DOU 16/05/2006, Seção 1.

CONTRERAS, José. Autonomia de professores. São Paulo: Cortez, 2012.

FRANCISCO BELTRÃO. Lei municipal n. 4240/2014. Dá nova redação ao Plano de Cargos e Carreira, Valorização e Remuneração dos Professores da Rede Municipal de Ensino (PCCR), de Francisco Beltrão-PR, 2014. 
FRANCO, Maria Amélia do Rosário Santoro. Pedagogia como ciência da educaşão. São Paulo: Cortez, 2008.

FRANCO, Maria Amélia do Rosário Santoro. Coordenação pedagógica: uma práxis em busca de sua identidade. Revista Múltiplas leituras, v. 1, n. 1, p. 117-131, jan. / jun. 2008.

KUENZER, Acacia Z. Trabalho pedagógico: da fragmentação a unitariedade possível. In: AGUIAR, Márcia Ângela da S.; FERREIRA, Naura Syria C. (orgs.). Para onde vão a orientação e a supervisão educacional? Campinas: Papirus, 2006.

LIBÂNEO, José Carlos. Organizaçãa e gestão da escola: teoria e prática. Goiânia: MF Livros, 2008.

LIBÂNEO, José Carlos. Pedagogia e pedagogos: para quê? São Paulo, Cortez, 2010.

MANACORDA, Mario Alighiero. Marx e a pedagogia moderna. Campinas: Editora Alínea, 2007.

SAVIANI, Dermeval. A pedagogia no Brasil: história e teoria. Campinas: Autores Associados, 2008.

SAVIANI, Dermeval. O choque teórico da Politecnia. Revista Trabalho, Educação e Saúde, 2003, v. 1, n. 1, p. 131-152.

WILLIAMS, Raymond. Marxismo e literatura. Rio de Janeiro: Zahar Editores, 1979.

Recebido em: 30 maio 2019 / Aprovado em: 21 nov. 2019

\section{Cite como}

MANARIN, Camila; PORTELINHA, Ângela Maria Silveira. O coordenador pedagógico frente aos desafios da constituição de sua profissionalidade Dialogia, São Paulo, n. 33, p. 192-204, set./dez. 2019. Disponível em: https://doi.org/10.5585/Dialogia.n33.14409. 